\title{
Limitations imposed by cloud cover on multitemporal visible band satellite data sets from polar regions
}

\author{
G.J. Marshall, W. G. Rees and J. A. Dowdeswell \\ Scott Polar Research Institute, University of Cambridge, Cambridge CB2 1ER, U.K.
}

\begin{abstract}
The study of surface features and processes on glaciers, ice caps and ice sheets often requires multitemporal data in order to take account of the dynamic behaviour of snow and ice. Satellite remote sensing provides an important means of acquiring such data sets from polar regions, but the effectiveness of visible (VIS) and near-infrared (NIR) wavebands is severely limited by the frequent presence of cloud cover. As well as preventing direct imaging of the surface, cloud cover can be difficult to discriminate from snow and ice because of its similarly high reflectivity. This paper describes a detailed quantitative study of the limitations imposed by cloud cover. The number of potentially useful images which could have been acquired from a study area in Svalbard for the April-September period for 1980-89 is determined. Meteorological data from two stations analyzed over this study period show that fewer than $10 \%$ of the available satellite overpasses occurred during cloud-free periods. A cloud cover level of three octas or less, used to define high quality imagery, occurred $29 \%$ and $32 \%$ of the time at the two stations. Markedly seasonal variations are found which can be explained in terms of the regional climate such that during the months August and September the probability of obtaining a cloud-free Landsat image every year is effectively zero. Analysis of several years of Landsat Quick Look images for other regions of Svalbard confirms these findings. However, a similar series for the Scoresby Sund region of East Greenland shows a much higher percentage of low cloud scenes and no marked seasonality.
\end{abstract}

\section{INTRODUCTION}

In many respects satellite remote sensing is an ideal technique for monitoring polar regions because the scale and remoteness of such places restrict the widespread undertaking of in situ experiments. The dynamic behaviour of snow and ice implies that a multitemporal data set can often provide the most satisfactory means of studying glaciological features and processes. For example, the estimation of glacier mass balance from the transient snow line altitude at the end of the melt season (e.g. Østrem, 1975) requires imagery taken at one particular time of year for as many years as possible. In contrast, the break up and formation of fast ice and the local movement of sea ice floes are relatively short-term events; to monitor them successfully requires imagery with a temporal resolution of less than one week.

Until recently the three main sensors with sufficiently high resolution for glaciological studies were the Multispectral Scanner (MSS) and Thematic Mapper (TM) carried by the Landsat series of satellites, and the High Resolution Visible (HRV) sensor on board the SPOT satellites. Their effectiveness in polar regions is constrained by three significant problems. For up to half the year high latitude areas experience extended periods when the sun remains very low or below the horizon. During this period the radiance reflected from the Earth's surface is negligible at the visible and infrared wave- lengths used by these sensors, making them ineffective. This time of inoperation is lengthened because imagery with solar elevations below $10^{\circ}$ is not normally acquired (USGS, 1979). In this study we remove this problem by considering only satellite data acquired between April and September, although useful imagery can occasionally be obtained outside this time. A second problem, the limitation caused by detector saturation, has been discussed in detail by others (Ferrigno and Williams, 1983; Dowdeswell and McIntyre, 1986) and is not considered in the present work.

The third problem, and the one addressed by this paper, is that of cloudiness. Polar regions experience widespread cloud cover and the inability of Landsat and SPOT sensors to penetrate cloud can severely impair their ability to supply multitemporal data sets. In addition, cloud, snow and ice all reflect highly at visible and nearinfrared wavelengths, and are therefore often difficult to distinguish from one another over large ice masses. Indeed Williams and Ferrigno (1988) reported that the EROS Data Center cloud cover assessment of archived MSS scenes from Antarctica is frequently unreliable, with snow often being mistaken for clouds. These problems are also applicable to HRV imagery (Massom, 1991). However, it has been found that cloud and snow can be separated by ratioing the middle-infrared TM bands 5 $(1.55-1.75 \mu \mathrm{m})$ and $7(2.08-2.35 \mu \mathrm{m})$. Orheim and Lucchitta (1987) studied a TM image of Antarctica and 
used two bands to discriminate between snow, high thin cirrus clouds composed of ice crystals, and low dense altocumulus clouds containing water droplets. These three surfaces have increasingly high albedos (Dozier, 1985), and snow therefore appears darkest at these wavelengths. Discrimination is, however, not usually a problem over many ice covered regions such as Svalbard or Alaska, where the existence of nunataks and other snow- and ice-free areas makes feature recognition much simpler.

In this paper we describe a detailed quantitative study of the limitations imposed by cloud cover on the effectiveness of VIS/NIR remote sensing in polar regions. Annual variations of cloud cover for the AprilSeptember period between 1980 and 1989 are described for an area of Svalbard. These meteeorological data are subsequently compared with Landsat overpasses in order to calculate the actual temporal resolution of good quality imagery. A comparison is then made with the impact of cloudiness on two other areas of Svalbard and a region of East Greenland, using multitemporal data sets of Landsat MSS Quick Look photographic prints. Finally, the relative merits and problems of using Synthetic Aperture Radar data as an alternative source of time-series imagery for the polar regions are discussed.

\section{STUDY AREAS}

The principal region used for this investigation is Nordenskiöld Land, part of central Spitsbergen, the largest island in the Arctic archipelago of Svalbard

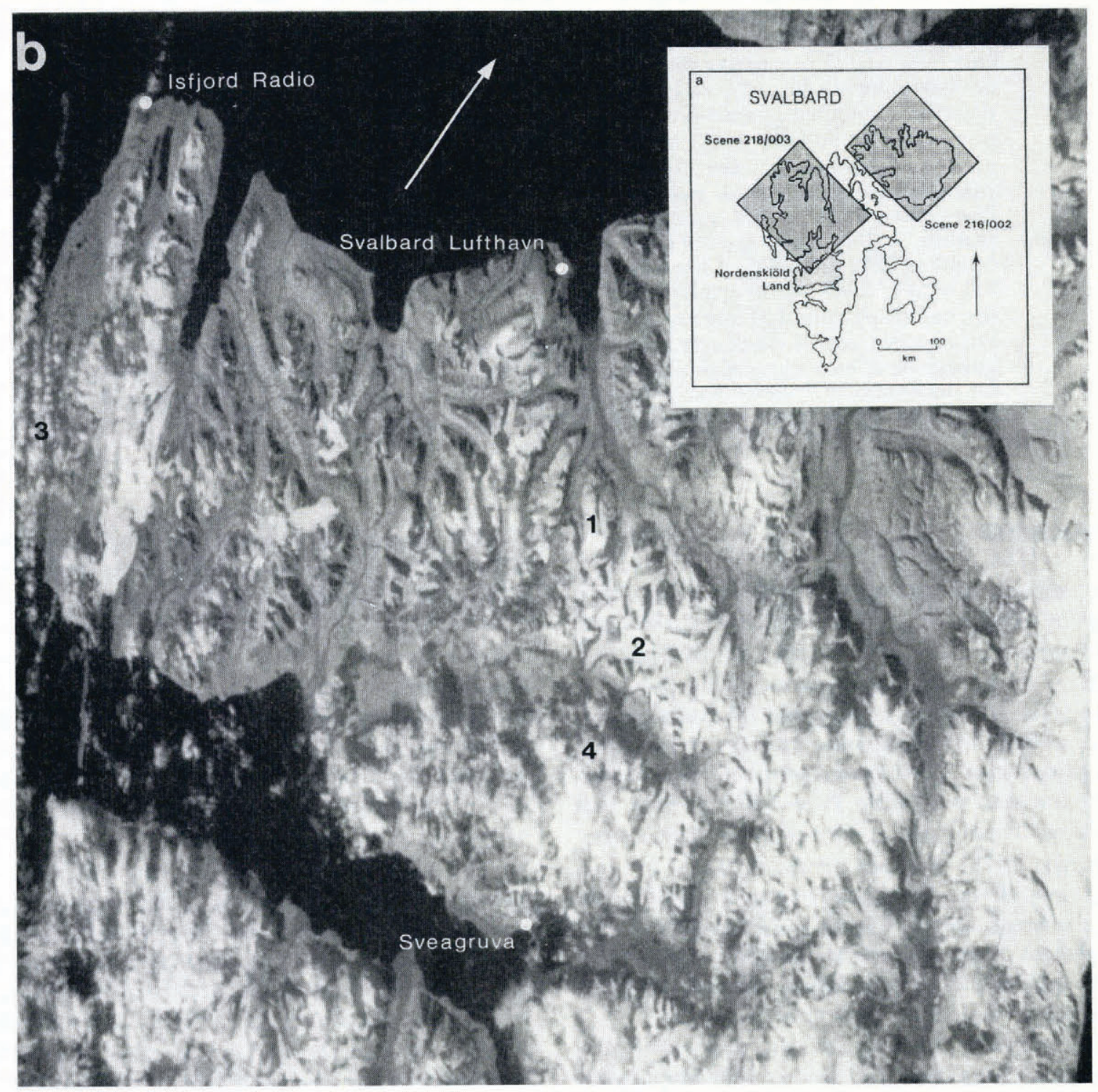

Fig. 1. (a) Map of Svalbard showing the Nordenskiöld Land study area, and the two Svalbard scenes used as a comparison. (b) Landsat MSS image of Nordenskiöld Land acquired on 24 August 1980, showing the meteorological stations from which data were used. The date of this image is towards the end of the melt season and the snow line can be seen towards the very top of many of the glaciers such as Foxfonna labelled (1) and Kokbreen (2). This is one of only ten possible MSS images of Svalbard Lufthavn from August during 1980-89 that has one octa or less cloud cover. Cloud is very limited indeed; there are some thin lines of altocumulus (3) over Nordenskiöldkysten, the strandflat to the west of the region, and much lower orographic clouds (4) together with their shadows, can be seen over the mountains to the south of Reindalen. 
(Fig. 1a).The study area lies between latitudes $77^{\circ} 40^{\prime} \mathrm{N}$ and $78^{\circ} 25^{\prime} \mathrm{N}$ and longitudes $13^{\circ} 35^{\prime} \mathrm{E}$ and $17^{\circ} 30^{\prime} \mathrm{E}$, and covers approximately $3500 \mathrm{~km}^{2}$. Nordenskiöld Land was chosen because the Scott Polar Research Institute has a number of ongoing projects based there, which will benefit substantially through the use of remotely sensed data. Figure $1 \mathrm{~b}$ is a Landsat MSS scene of Nordenskiöld Land imaged on 24 August 1980. Ten years of cloud cover data, from 1980-89, were available from the Norske Meteorologiske Institutt for Svalbard Lufthavn and Sveagruva, the two meteorological stations currently operating on Nordenskiöld Land (Fig. 1b).

In order to analyze the impact of cloud cover in other areas, sequences of Landsat Quick Look photographic prints from three different scenes were studied. Two of these are also located over Svalbard; 218/003 from northwest Spitsbergen and 216/002 from Nordaustlandet (Fig. 1a). The other scene, 227/010, covers an area of the Scoresby Sund region of East Greenland and has nominal centre coordinates of $70^{\circ} 55^{\prime} \mathrm{N}, 24^{\circ} 20^{\prime} \mathrm{W}$.

\section{GLOUD GOVER ANALYSIS}

Cloud cover data were obtained from meteorological stations and Landsat Quick Look photographic prints. For this analysis only cloud cover levels of three octas or less were examined. Although this is an arbitrary figure, experience has shown that imagery having greater cloudiness is unlikely to prove useful for glaciological studies of the study areas, and therefore it is used to define potentially useful or high quality imagery. The percentage frequencies of days when zero, less than or equal to one, two and three octas cloud cover occurred at $1300 \mathrm{~h}$ local time were obtained for Svalbard Lufthavn and Sveagruva meteorological stations over the ten-year study period. This time is within 39 minutes of all the local crossing times of the Landsat and SPOT series of satellites. A sample autocorrelation analysis of cloud cover showed no significant change over a 39 minute period and therefore the two data sets were compared directly. A comparison of 40 Quick Looks with meteorological data over a five-year period revealed no significant difference in the estimate of cloud cover from these two techniques. This indicates that point meteorological data can give a statistically valid representation of cloud cover distribution for a whole Landsat scene over this period of time. Cloud cover is obtained from the Quick Looks by using a grid and estimating to the nearest octa. Although this is somewhat subjective, the study areas contain many regions which are snow and ice free and the difficulties of discriminating between snow, ice and cloud, as discussed earlier, are not serious. The accuracy required in this particular study did not justify a more thorough approach using automated techniques.

\section{Cloud cover variations for April-September}

The percentage frequencies of three octas or less cloud being present during April to September are $22 \%$ and $24 \%$ at Svalbard Lufthavn and Sveagruva, respectively. Therefore, as an average over the whole study period, it appears that acquisition of potentially useful satellite a)

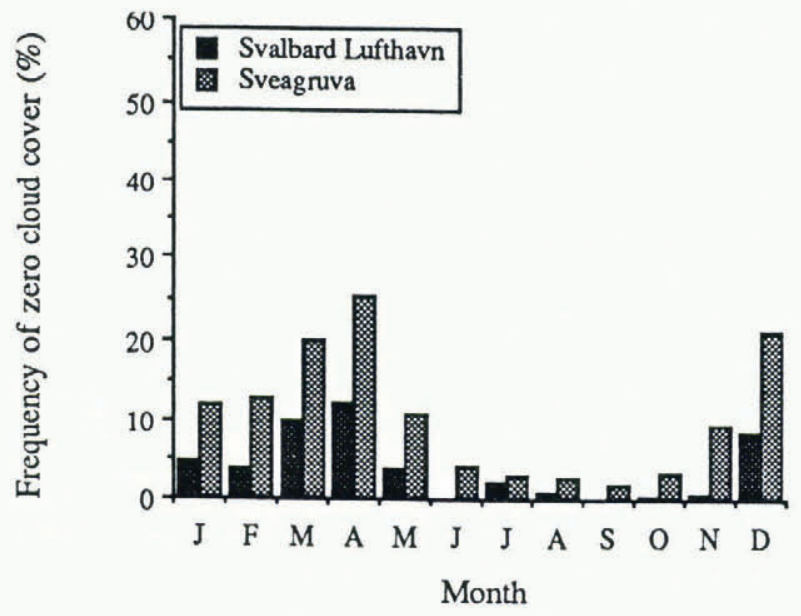

b)

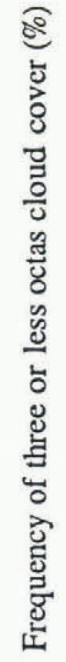

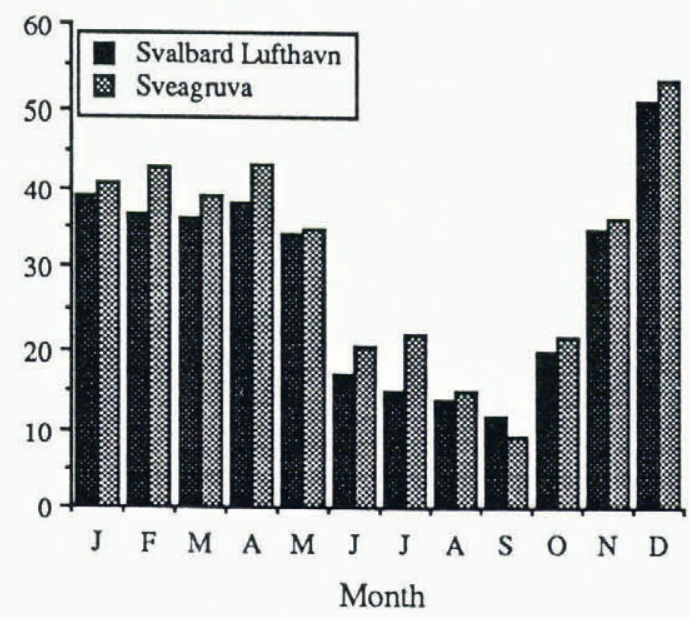

Fig. 2. Percentage frequencies of monthly cloudiness at Svalbard Lufthavn and Sveagruva during 1980-89. The cloud cover levels illustrated are (a) zero octas and (b) three octas or less.

imagery is possible for between two and three days out of ten.

Cloud cover data for the whole year were examined to demonstrate any annual variations, and to place the April-September period in its annual context. Monthly values for the percentage frequencies of zero and three octas or less cloud cover are shown in Figure 2. The data for zero cloud cover (Fig. 2a) indicate that Sveagruva has a higher frequency of this level of cloud cover than Svalbard Lufthavn in all months. Svalbard Lufthavn had no cloud-free days at $1300 \mathrm{~h}$ in either June or September for the entire ten-year study period. The lowest value for Sveagruva is $2 \%$ and occurs in September. Both stations have their highest number of cloud-free days in April, $12 \%$ and $25 \%$ for Svalbard Lufthavn and Sveagruva respectively. A comparison of the data for three octas or less cloud cover (Fig. 2b) shows a marked similarity between the two stations. Both have a minimum for this level of cloud cover in September and a maximum in December. The percentage frequencies of three octas or less in September and December are $12 \%$ and $51 \%$ at Svalbard Lufthavn and $9 \%$ and $53 \%$ at Sveagruva.

During a year there is a marked bimodal distribution in the frequency of all levels of cloud cover studied at both 
stations, especially for those greater than zero. The period from November to May has relatively more days with less cloud cover whereas from June to October greater cloud cover predominates (Fig. 2b). The higher values of cloudiness in summer are closely associated with a meridional circulation which tends to continue into autumn (Wishman, 1966). This is characterized by many northerly-moving cyclones and a northward extension of warmer and moister air masses. The significant decrease in cloudiness with the onset of winter corresponds to a reduced frequency of meridional types and a southerly displacement of areas of high cyclone frequency (Wishman, 1966). Cold and dry air masses from the polar basin often reach Svalbard, and at this time of year the climate has a continental character.

Yearly data indicate that in 1984 there were substantially fewer days with little cloud cover than the annual mean over the study period. The frequency of three octas or less cloud cover at Svalabrd Lufthavn was $19 \%$ compared to the average of $29 \%$, and at Sveagruva the two values were $19 \%$ and $32 \%$, respectively. There was significantly more cloud cover at both the beginning and end of the year in 1984 than for other years, probably caused by the frontal zone being displaced northwards, thus allowing early establishment and then continuation of the meridional circulation to the south. Variation between the other years of the study period is within $11 \%$.

\section{GLOUD COVER AND LANDSAT DATA ACQUIS- ITION}

\section{Method}

The effect of cloudiness on the potential of Landsat satellite orbits to provide useful imagery is analyzed by comparing the cloud cover distribution to the actual overpasses by satellites during the study period. The probability of acquiring high quality imagery for each month during the April-September period is then calculated.

If the probability that a single image is cloud-free (according to a suitable criterion such as, for example, one octa or less of cloud cover) is $p$, the probability $P$ of obtaining a satisfactory image from $n$ observations is

$$
P=1-(1-p)^{n}
$$

This expression, which assumes that cloud-free events are independent and drawn from a normal distribution, can be rearranged to give the number $n$ of observations required:

$$
n=\frac{\log (1-P)}{\log (1-p)}
$$

In practice the assumption of a normal distribution of independent events is incorrect, so the determination of a suitable value of $P$ is empirical. In a similar study of the USA, Goetz (1979) found that taking $P=0.75$ gave a reasonably good fit to the observed values of $n$ with $p$, so that (for example) $n \approx 13$ if $p=0.1$.

\section{Landsat orbit considerations}

To undertake a similar analysis for the Spitsbergen study, the number of passes made by Landsat satellites over the metorological stations during the study period was calculated for the periods when the MSS was operational. TM data were not considered because they are not available throughout the entire study period. Landsat has a swath width of only $185 \mathrm{~km}$ and this parameter, together with the repeat interval of 18 days for Landsats 1-3 or 16 days for Landsats 4 and 5, causes irregular coverage at high latitudes. The convergence of orbits towards the poles does, however, increase the number of days of coverage with increasing latitude. In addition, for most of the study period there were two Landsat satellites operating simultaneously.

Svalbard Lufthavn and Sveagruva were imaged by nine and ten consecutive orbits of Landsats 2 and 3, respectively, and therefore had $100 \%$ and $111 \%$ daily coverage when both satellites were operational; i.e. Sveagruva had two daily overpasses on every ninth day. There were also some days between July 1982 and February 1983 when Svalbard Lufthavn and/or Sveagruva had an overpass by both Landsat 3 and Landsat 4 . Orbital coverage at this latitude was significantly reduced with the change to the 16 day repeat cycle of Landsats 4 and 5 with both stations imaged by only four orbits. This phenomenon is a function of the parameters of the sunsynchronous orbit and the latitude of the stations (Rees, 1992). The net result, with both satellites operational, provides a $50 \%$ daily coverage.

The number of orbits for the April-September period from 1980 to 1989 for which the two stations had a Landsat overpass with operational MSS is shown in Figure 3. Sveagruva had a greater number from 1980-82 because of the additional tenth orbit of Landsats 2 and 3 . Although both stations had complete daily coverage or better if Landsat 2 and 3 were both functioning simultaneously, Figure 3 shows that this potential was realized only in 1981 (there are 183 days in the AprilSeptember period), due to operational problems in other years. The relatively small number of overpasses in 1983 is because Landsat 4 was the only satellite operating for most of that year. Landsat 4 and 5 both worked
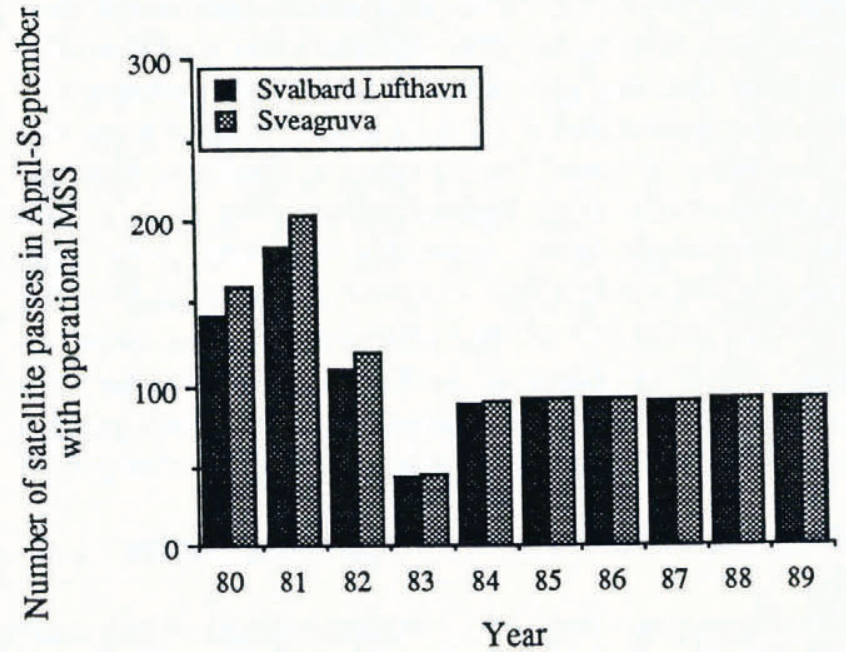

Fig. 3. Number of Landsat overpasses with operational MSS over Svalbard Lufthavn and Sveagruva for AprilSeptember during 1980-89. 
continuously from 1985-89 so the number of overpasses over each station is identical for these years.

\section{Results}

Similar calculations were completed for each individual month. It can be seen that the monthly pattern of temporal resolution was the same at Svalbard Lufthavn and Sveagruva, with April having the highest frequency of high quality imagery and August the lowest. The average temporal resolution in April was 7 days at both stations. However, in August this figure increased to 42 days and 53 days at Svalbard Lufthavn and Sveagruva, respectively. This implies that there is unlikely to be an image with one octa or less cloud cover available for August in any one year. The same is also true, although to a lesser extent, for September at Sveagruva, and for both September and July at Svalbard Lufthavn.

\section{LIMITATIONS IMPOSED BY GLOUD GOVER IN OTHER POLAR REGIONS}

In order to study the effect of cloud cover on image availability from other areas, multitemporal data sets of Landsat MSS Quick Look photographic prints were studied for three scenes, two in other regions of Svalbard (Fig. 1a) and one from East Greenland. The Svalbard scenes were 218/003 of northwest Spitsbergen, with data from 1985 to 1990, and 216/002 from Nordaustlandet, with data from 1985 to 1988 . These two data sets have a large variation in the number of images available from different years, making interannual comparison difficult. The Greenland scene, 227/010, covers part of the Scoresby Sund region in the east of the island. For this scene, $227 / 010$, data from 1988 to 1990 were available.

\section{Svalbard data}

The variation of cloud cover for scene 218/003 (northwest Spitsbergen) from April to September is illustrated in Figure $4 \mathrm{a}$. The month when cloudiness is least is May, while the period from June to early August has very few images with three octas or less cloud cover. The average cloud cover within the imagery decreases after this period. Overall, $20 \%$ of the images have a cloud cover of three octas or less. Figure 5 a contrasts the frequency of cloud cover in May imagery (least cloudy month) with that in July (most cloudy month). Both months have nine scenes in the 1985-90 Quick Look data set. Five images in May have three or less octas cloud cover whereas in July there are none. However, three images in May have a cloud

a)

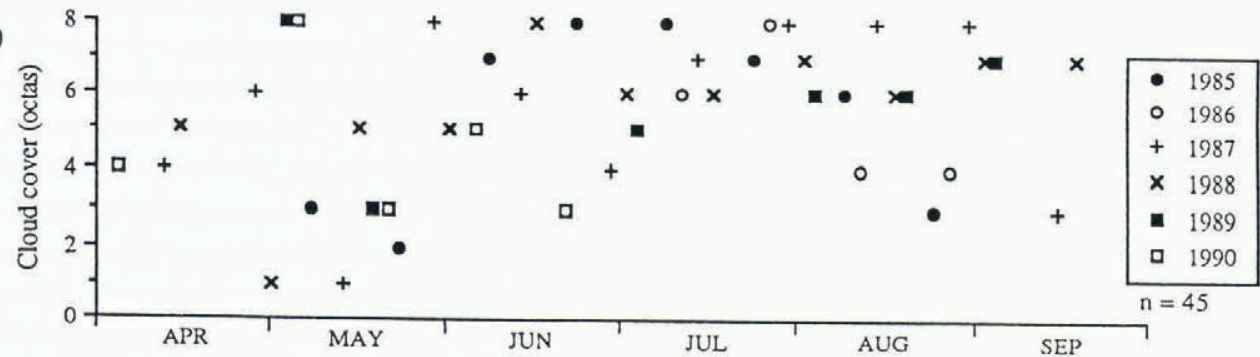

b)

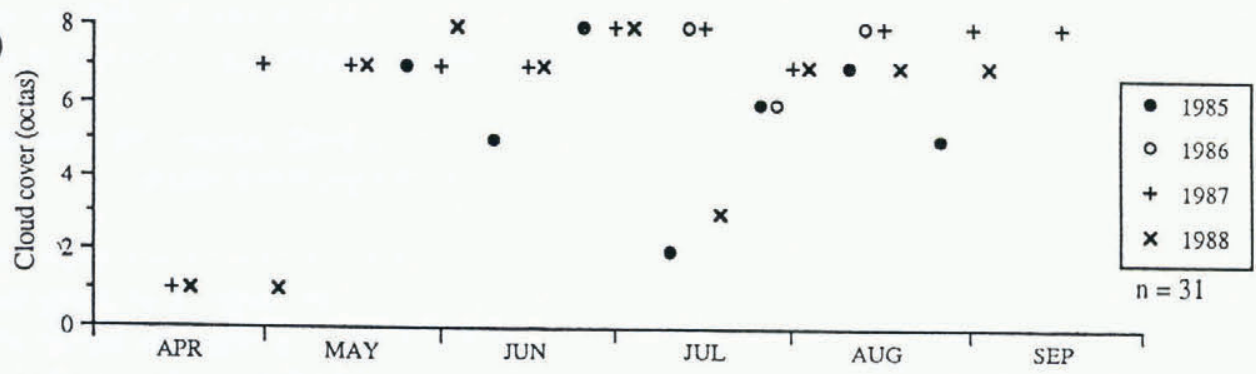

c)

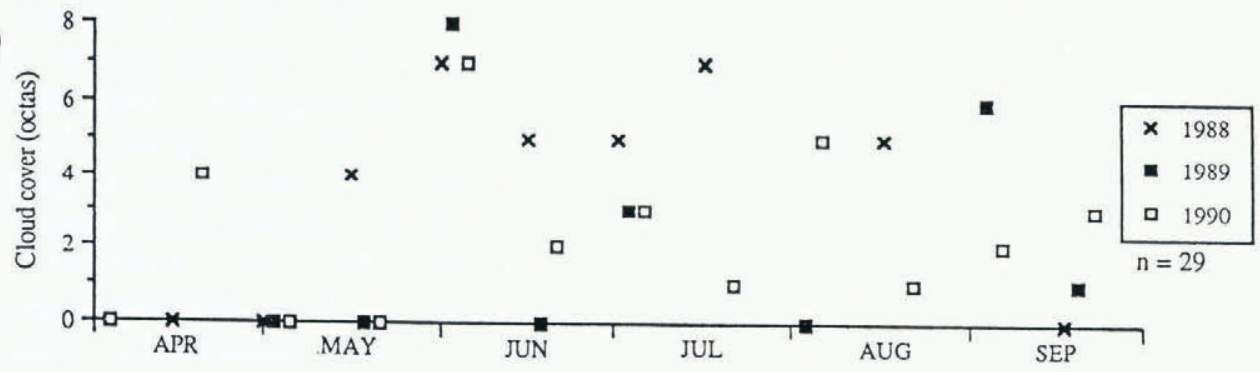

Fig. 4. The variation of cloudiness for April-September in Landsat Quick Look imagery for (a) scene 2181003 from northwest Spitsbergen (1985-90), (b) scene 216/002 from Nordaustlandet (1985-88), and (c) scene 227/010 from the Scoresby Sund region of East Greenland (1988-90). 
a)

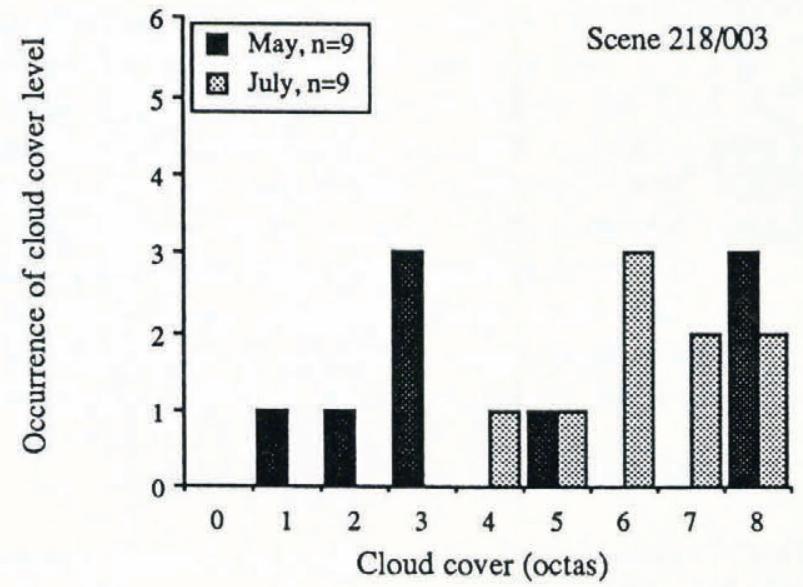

b)

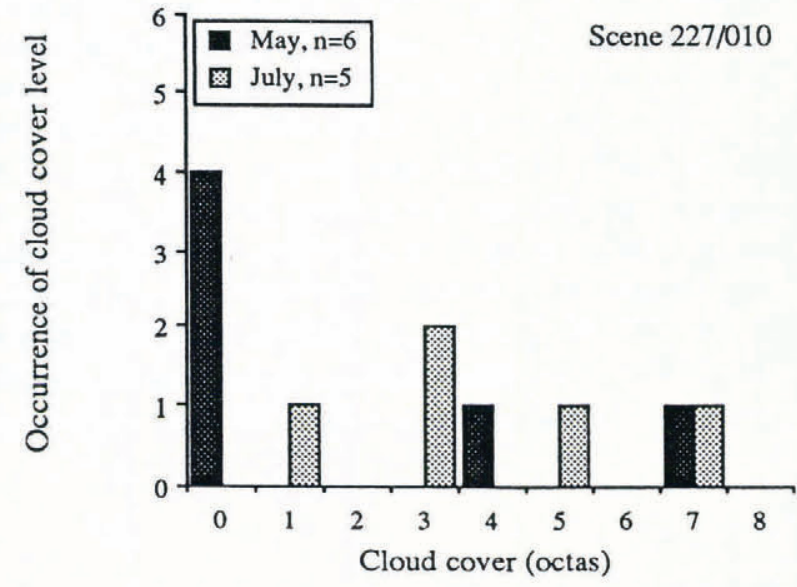

Fig. 5. Cloudiness levels in Landsat imagery from May and Fuly for (a) scene 218/003 from northwest Spitsbergen (1985-90) and (b) scene 227/010 from East Greenland (1988-90).

cover of eight octas, emphasizing the point that high quality imagery (i.e. three octas or less) cannot be relied upon at any time of the year. Seven July images have a cloud cover or at least six octas, making useful VIS/NIR imagery difficult to obtain.

When compared with data from the northwest Spitsbergen scene, there is clearly a much greater percentage of images with very high cloud cover levels for scene 216/002 from Nordaustlandet in northeast Svalbard (Fig. 4b). 67\% of the images have at least seven octas of cloud and only $15 \%$ have three or less. Three of these high quality images are in April and May, while the other two are in July. This is in contrast to scene $218 / 003$ (Fig. 4a), as is the fact that there is no reduction in the cloud cover levels in August and September.

\section{Greenland data}

The East Greenland scene (Fig. 4c) exhibits a marked contrast with the Svalbard scenes in two ways. Firstly, there is a much higher percentage of images with lower cloud cover levels; $62 \%$ of the images have cloud cover of three octas or less. This is about three times greater than for the Svalbard imagery. Secondly, these images appear in all months between April and September; that is, there is little if any seasonality in cloud cover for the Scoresby Sund region. This is illustrated in Figure 5b, which shows the distribution of cloud cover levels in imagery from May and July for scene 227/010. Four out of six May images have zero cloud and three out of five July images have three octas or less of cloud cover. Both months also have one image with seven octas. Therefore, although May is probably the better month for imagery because of the large number of cloud-free scenes, July does have a relatively large number of scenes with sufficiently little cloud cover to acquire useful information. This contrasts with Figure 5a for northwest Spitsbergen which shows an appreciable difference between May and July. Both the overall probability of acquiring good imagery in the April-September period in any one year, and in most months of this period, are higher for East Greenland than Svalbard.

\section{DISCUSSION}

\section{Comparison with a previous study in the Alps}

If a cloud cover of three octas is taken as the definition of potentially useful satellite imagery, then during the decade from 1980 to 1989 , such data could be acquired over Nordenskiöld Land in Spitsbergen for the AprilSeptember period for between two and three days out of ten. This gives similar results to the study by Rott and others (1988), who examined the effects of cloudiness on the availability of Landsat imagery of the central and eastern Alps. During the snowmelt season, from 1 April to 30 June, with two Landsat satellites operational, there was a potential of ten images for the Alps. However, the number of useful images, including those that were partly cloud covered, actually available was three per season and these occurred at irregular intervals. The authors concluded that this number would still be sufficient for some operational tasks in Alpine glacierized basins provided the images were received at particular dates.

\section{Impact of cloud cover on the effectiveness of visible band satellite data}

Many glaciological studies are such that even imagery available at fairly large and irregular time intervals provides sufficient coverage for useful work to take place. Examples include the analysis and classification of ice surface topography (e.g. Dowdeswell and McIntyre, 1987), the monitoring of ice margin fluctuations (e.g. Dowdeswell, 1986) and ice velocity measurements (e.g. Lucchitta and Ferguson, 1986). However, this is not always the case and regular data are a necessary requirement for some types of glaciological research. Measurement of the snow line altitude for mass balance calculations has to be completed at the end of the measurement year, usually taken to be around 1 October in the northern hemisphere (Paterson, 1981). In Nordenskiöld Land, September has the lowest annual percentage frequencies of low cloud-cover amounts. For example, the values of zero and three or less octas of cloud-cover levels for the study period are only $0 \%$ and 
$9 \%$, and $2 \%$ and $12 \%$ at Svalbard Lufthavn and Sveagruva, respectively (Fig. 2). Hence, if a synoptic scale measurement of the equilibrium line over Nordenskiöld Land was required every year, then Landsat imagery would be unlikely to fulfil such a requirement. The data obtained by using binomial statistics show that an image with one octa or less cloud cover can be expected only approximately every 40 days over Nordenskiöld Land at this time of the year. However, the additional availability of SPOT HRV data means that much finer temporal resolutions are probable.

Another glaciological process requiring good multitemporal data if it is to be successfully monitored is the break up and formation of fast ice in fjords and coastal areas. Fast ice formation usually takes place late in the year, when imagery is often degraded by low light levels. The time of year at which breakup occurs varies between different years, so a high likelihood of the availability of useful imagery over a period of several weeks is required to ensure that this process is successfully imaged. We have found that the Landsat Quick Look images from the Scoresby Sund region of Greenland are sufficient for this purpose. The breakup of fast ice, firstly in the narrow and deeper inner fjords in early June, and then subsequently in the wider but shallower outer fjord, during late June and early July, can be monitored successfully in 1990 with imagery acquired every sixteen days. Partial monitoring can be achieved in 1988 and 1989. If a similar study was required for Isfjorden, the fjord complex north of Nordenskiöld Land in Spitsbergen, then the greater cloud cover over this area during this time of year would probably prevent its successful completion. Preliminary Landsat data searches for Zemlya Frantsa Iosifa (Franz Josef Land) in the Russian high Arctic indicate that the impact of cloud cover on imagery of this area is markedly worse than in Svalbard, with very little imagery with three octas or less cloud cover being available. The effectiveness of satellites using visible and near-infrared bands in polar regions is therefore very much dependent upon the particular synoptic climatology of the study area.

\section{COMPARISON WITH SYNTHETIC APERTURE RADAR DATA}

Unlike visible and near-infrared sensors, Synthetic Aperture Radars (SAR) operate independently of daylight and cloud cover. A SAR emits a very short pulse of radar radiation and analyzes the time-frequency structure of the returning signal to determine the back-scattering coefficient $\sigma^{\circ}$ of the surface, with a spatial resolution comparable to the sensors of Landsat and SPOT. The ERS-1 SAR, for example, achieves a spatial resolution of 20 to $30 \mathrm{~m}$. At its operating frequency of $5.3 \mathrm{GHz}$ the presence of even a thick layer of cloud or a large rain cell introduces less than $1 \mathrm{~dB}$ attenuation (Rees, 1990).

There are, however, several problems with the use of SAR imagery for the multitemporal study of polar regions. Until the launch of ERS-1 in 1991, no satellite carrying a SAR had been placed in a near-polar orbit since Seasat in 1978 (highest latitude $72^{\circ}$ ), so there is as yet no satellite data set covering even one annual cycle. In addition, SAR data are not directly comparable with VIS/NIR data because of geometric distortions in areas of high relief. Interpretive difficulties are also caused by speckle and the penetration of radar into the snowpack. The analysis of variations in backscattering coefficients to yield glaciologically useful information is still unclear, largely because of this lack of imagery and also of validating data. These problems should, however, be overcome with the availability of ERS-1, JERS-1 and, in the near future, Radarsat SAR data. A number of technological limitations also currently apply to the acquisition of SAR data limiting its temporal resolution. However, the disadvantage is more than offset by insensitivity of SAR to cloud or darkness.

\section{CONCLUSIONS}

The principal conclusions derived from this study are as follows:

1. The Spitsbergen study area has a potential of high quality visible-infrared satellite imagery (with a cloud cover of three or less octas) during April-September for between two and three days out of ten. For cloud-free imagery this value is less than one day out of ten.

2. Annual variations of cloudiness for the study area show a marked bimodal distribution, with the period from June to October having the greatest cloud cover. Within the April-September period, for the years 1980 89, the temporal resolution of Landsat MSS imagery with one or less octas cloud cover varied from seven days in April to about 50 days in August. The figure was approximately 40 days in September. This has important implications for measurements relating annual mass balance to the snow- line altitude at the end of the measurement year, as it is unlikely that such imagery will be acquired every year. However, the additional availability of HRV data means that potentially finer temporal resolutions are possible.

3. The effectiveness of sensors using visible and infrared bands in the polar regions is very much dependent upon the particular synoptic climatology of an area. This will influence both the number of high quality images acquired, and the time of year when such imagery is available, which in turn will affect the nature of glaciological studies possible for a particular area.

4. When multitemporal imagery is required, either at certain times of the year when cloudiness is a problem or for monitoring rapid processes, then Synthetic Aperture Radar data, with its inherent interpretation difficulties, might well be the only valuable remotely-sensed data obtainable.

\section{ACKNOWLEDGEMENTS}

We thank the Norske Meteorologiske Institutt for supplying the cloud cover data from Svalbard stations. The satellite image photography was prepared by M. R. Gorman. G.J. Marshall acknowledges support from a U.K. Natural Environment Research Council research studentship. 


\section{REFERENCES}

Dowdeswell, J. A. 1986. Remote sensing of ice cap outlet glacier fluctuations on Nordaustlandet, Svalbard. Polar Res., 4(1), 25-32.

Dowdeswell, J.A. and N.F. McIntyre. 1986. The saturation of Landsat MSS detectors over large ice masses. Int. 7. Remote Sensing, 7(1), 151-164.

Dowdeswell, J.A. and N. F. McIntyre. 1987. The surface topography of large ice masses from Landsat imagery. J. Glaciol., 33(113), 16-23.

Dozier, J. 1985. Snow reflectance from Thematic Mapper. In Landsat-4 science characterization early results. Vol. IV. Applications. Washington, DC, National Aeronautics and Space Administration, 349-357. (NASA Conference Publication 2355.)

Ferrigno, J. G. and R. S. Williams, Jr. 1983. Limitations in the use of Landsat images for mapping and other purposes in snow- and ice-covered regions. In Proceedings of the 17th International Symposium on Remote Sensing of the Environment, Ann Arbor, Michigan. Vol. 1, 335-355.

Goetz, A.F.H. 1979. Preliminary stereosat mission description. JPL Publ. 720-33.

Lucchitta, B. K. and H. M. Ferguson. 1986. Antarctica: measuring glacier velocity from satellite images. Science, 234(4780), 1105-1108.

Massom, R. 1991. Satellite remote sensing of polar regions. London, Belhaven Press.
Orheim, O. and B. K. Lucchitta. 1987. Snow and ice studies by Thematic Mapper and multispectral scanner Landsat images. Ann. Glaciol., 9, 109-118.

Østrem, G. 1975. ERTS data in glaciology — an effort to monitor glacier mass balance from satellite imagery. $\mathcal{J}$. Glaciol., 15(73), 403-415.

Paterson, W.S.B. 1981. The physics of glaciers. Second edition. Oxford, etc., Pergamon Press.

Rees, W. G. 1990. Physical principles of remote sensing. Cambridge, etc., Cambridge University Press.

Rees, W. G. In press. Orbital subcycles for Earth remote sensing satellites. Int. F. Remote Sensing.

Rott, H., C. Mätzler, D. Strobl, S. Bruzzi and K. G. Lenhart. 1988. Study on SAR land applications for snow and glacier monitoring. Paris, European Space Agency. (ESA Contract Report 6618/85/F/FL(SC).)

U.S. Geological Survey. 1979. Landsat data users' handbook. Revised edition. Sioux Falls, SD, U.S. Geological Survey.

Williams, R.S., Jr and J. G. Ferrigno. 1988. Landsat images of Antarctica. U.S. Geol. Surv. Prof. Pap. 1386-B, 139-278.

Wishman, E. 1966. A comparison between the general circulation over the Svalbard area and the weather conditions at Isfjord Radio. Nor. Polarinst. Skr. 136.

The accuracy of references in the text and in this list is the responsibility of the authors, to whom queries should be addressed. 